\title{
IM BASED SPEED SERVODRIVE WITH LUENBERGER OBSERVER
}

\author{
Juraj Gacho — Milan Žalman *
}

\begin{abstract}
The article concerns observing states of the Induction Motor (IM) using a Luenberger observer in the speed servo drive. The movement of the motor and observer roots is analyzed for a variable speed. Following the analysis, a new method for gain evaluation of the IM magnetic flux observer is presented. This structure is extended by including an adaptive speed observer. The functionality of the presented method is proved in simulations using MATLAB Simulink.

K e y w o r d s: induction motor, sensorless speed control, Luenberger observer
\end{abstract}

\section{INTRODUCTION}

Dynamic control of the IM belongs to the dominant applications in the movement control area. In the field of IM control there are two noticeable two trends. The first one is the control with limited measurability of the state variables (without measuring mechanical quantities - Sensorless Control) mainly in speed drives, where the main accent is put to the quality of the state variables observing. The term sensorless means in this context that sensors of mechanical quantities (position, speed, acceleration, torque) are not used. But if a given control structure needs to have information about these quantities, they are obtained from observers. Electrical quantities like currents and voltages are measured in these systems. The reason for using sensorless control is that it is not necessary to mount further sensors of mechanical quantities that would lead to higher costs. Furthermore the mechanical sensor can be a next source of faults (mainly in hostile environment). Using observers it is possible to replace the older IM control types (scalar control) by superior control types (for example vector control) only by changing the control algorithm.

The second trend is the closed loop dynamic control with focus on the speed and quality of the transient states with a feedback also from mechanical quantities of the IM (like position, speed). This approach is used mainly in position systems.

In both approaches it can happen that for high-quality control also state values are needed which are not easily measurable in the particular structure and hence such values have to be observed.

There are many methods to observe the angular speed and also further quantities needed for IM control (for example the magnetic flux) and also many methods to observe system parameters.

These methods can be divided into a few groups. There are estimators (open loop), which use the model of the systems and also known parameters for the estimation.
Hence changes of the parameters have a strong influence on the estimation precision. That is the reason why such estimators are used only rarely. A few of such estimators are mentioned in [1], [2].

Probably the largest group of the observers are based on MRAS systems which use reference and adaptive models. Description and applications of the MRAS observers can be found in [1], [2], [3], [4], [5], and many other works.

Applications using the extended Kalman filter (EKF) are also often used for IM states observing. The extended Kalman filter for observing angular speed and magnetic flux can be found in [6], [7], [2]. The use of an extended Luenberger observer for observing quantities of the AM can be found in [8], [9], [10], [2]. This article concerns the extended Luenberger observer for observing the IM rotor magnetic flux in a speed servodrive structure with an adaptive speed observer. In the article the calculation is derived of the observer gains for an arbitrary position of the observer poles and also a new method for observer pole placement is introduced for observing the IM rotor magnetic flux.

\section{SPEED SENSORLESS DRIVE STRUCTURE}

The base of the servodrive will be a squirrel cage IM. The IM model in the stator coordinate system with state variables $\hat{i}_{s}, \hat{\psi}_{r}$ will be used. This model can be described as

$$
\begin{aligned}
\frac{\mathrm{d} \mathbf{x}}{\mathrm{d} t} & =\boldsymbol{A x}+\boldsymbol{B u} \\
\boldsymbol{y} & =\boldsymbol{C} \boldsymbol{x}
\end{aligned}
$$

where respective matrices are

* Institute of Control and Industrial Informatics, Slovak University of Technology in Bratislava, Faculty of Electrical Engineering and Information Technology, Ilkovičova 3, 81219 Bratislava, Slovakia, juraj.gacho@amit.sk, milan.zalman@stuba.sk 


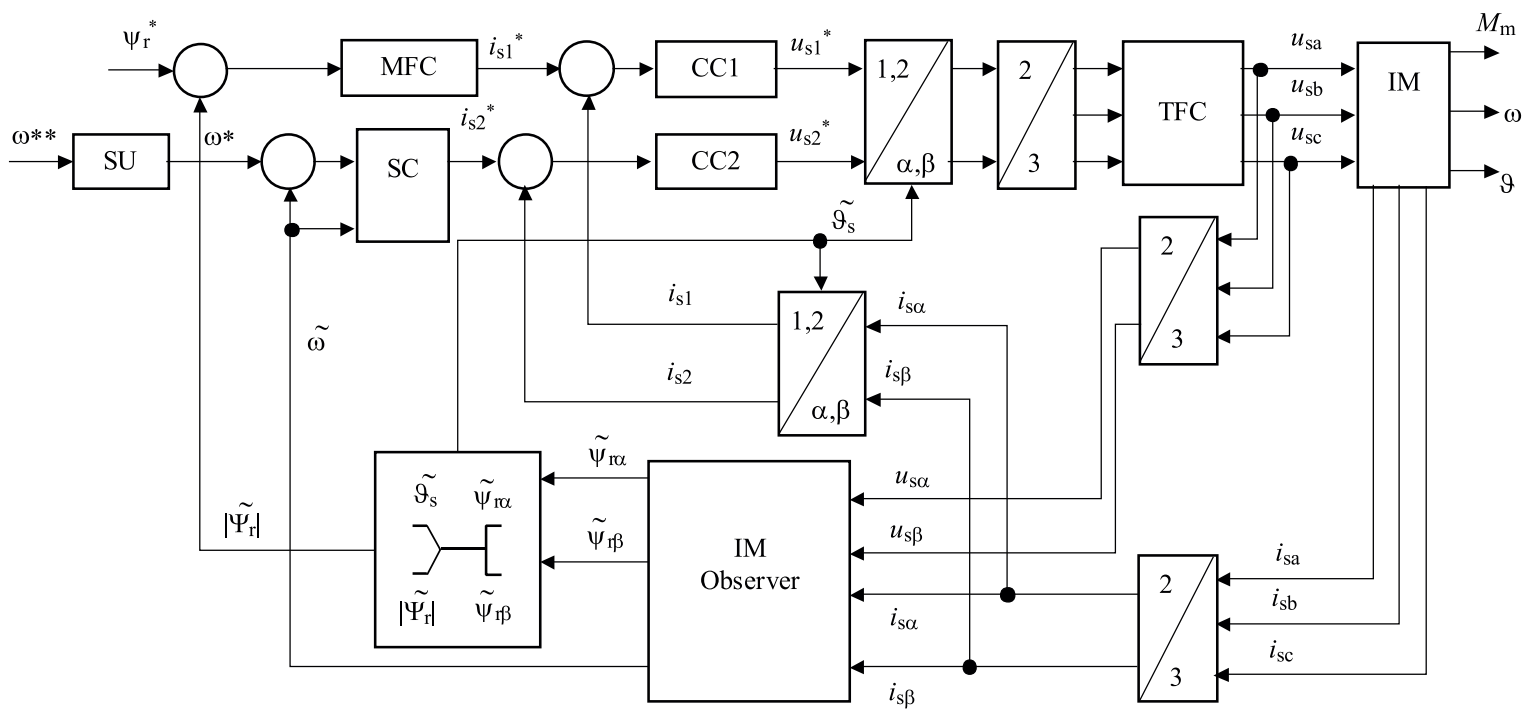

Fig. 1. Speed servodrive structure with state variable observing: SU - Starting unit (for smooth required angular speed slope, CC1, CC2 - PS current controllers, MFC - PS magnetic flux controller, SC - speed controller

$\mathbf{x}=\left[\begin{array}{c}\hat{i}_{s} \\ \hat{\psi}_{r}\end{array}\right] ; \quad \boldsymbol{A}=\left[\begin{array}{cc}-\frac{1}{T_{1}} & \left(\frac{k_{r}}{T_{r} L_{s}^{\prime}}-j \frac{k_{r} \omega}{L_{s}^{\prime}}\right) \\ \frac{L_{m}}{T_{r}} & \left(-\frac{1}{T_{r}}+j \omega\right)\end{array}\right]=\left[\begin{array}{ll}a_{1} & a_{2} \\ a_{3} & a_{4}\end{array}\right]$

$\boldsymbol{B}=\left[\begin{array}{c}\frac{1}{L_{s}^{\prime}} \\ 0\end{array}\right] ; \quad \boldsymbol{C}=\left[\begin{array}{ll}1 & 0\end{array}\right]$

where

$R_{1}=R_{s}+R_{r} \frac{L_{m}^{2}}{L_{r}^{2}}, \quad T_{1}=\frac{L_{s}^{\prime}}{R_{1}}, \quad T_{r}=\frac{L_{r}}{R_{r}}, \quad k_{r}=\frac{L_{m}}{L_{r}}$

$$
\sigma=1-\frac{L_{m}^{2}}{L_{s} L_{r}}, \quad L_{s}^{\prime}=\sigma L_{s}
$$

In Tab.1 the symbols used in the IM model are described.

Table 1. Symbols used in the IM model

\begin{tabular}{l}
\hline$u_{s}-$ Stator voltage \\
$i_{s}-$ Stator current \\
$\Psi_{s}-$ Stator magnetic flux \\
$R_{s}-$ Stator resistance \\
$L_{s}-$ Stator inductance \\
$u_{r}-$ Rotor voltage \\
$i_{r}-$ Rotor current \\
$\Psi_{r}-$ Rotor magnetic flux \\
$R_{r}-$ Rotor resistance \\
$L_{r}-$ Rotor inductance \\
$L_{m}-$ Magnetizing inductance \\
$\omega-$ lectrical angular speed \\
$\omega_{s}-$ Synchronous electrical angular speed \\
$\omega_{m}-$ Mechanical angular speed \\
$\vartheta \quad$ Electrical rotor angle \\
$p^{\prime}-$ Number of the pole pairs \\
$\sigma \quad-$ Leakage factor \\
\hline
\end{tabular}

Used control structure for the speed servodrive with IM is presented in Fig. 1.

This article concerns mainly the IM observer block.

\section{LUENBERGER OBSERVER}

The Luenberger observer (LO) belongs to the group of closed loop observers. It is a deterministic type of observer because it is based on a deterministic model of the system. The basic LO is suitable only for linear time invariant system. This can be expressed as

$$
\frac{\mathrm{d} \tilde{\mathbf{x}}}{\mathrm{d} t}=\boldsymbol{A} \tilde{\boldsymbol{x}}+\boldsymbol{B u}+\boldsymbol{K}(\boldsymbol{y}-\boldsymbol{C} \tilde{\boldsymbol{x}})
$$

where $\tilde{\boldsymbol{X}}$ is the vector of the observed state quantities and $\boldsymbol{K}$ is the observer gain matrix.

If the IM model is expressed in the stator coordinate system and if the elements of the stator current and rotor magnetic flux are chosen as state variables (equations (1), (2)), then we can talk about a time variant model because the parameters of the model can vary in time (due to changes of the angular speed). Since the basic LO is not suitable for the described type of system it is inevitable to use extended Luenberger observer (ELO). The ELO (unlike the basic LO) can be used also for nonlinear and time variant systems.

The ELO design consists of two steps - appropriate selection of the observer poles and then calculation of the observer gain matrix $\boldsymbol{K}$.

For observing the elements of the rotor magnetic flux vector via ELO algorithm an IM model will be used expressed by equations (1).

Then the observer matrix can be written as

$$
\boldsymbol{A}_{0}=\boldsymbol{A}-\boldsymbol{K} \boldsymbol{C}=\left[\begin{array}{cc}
\left(-\frac{1}{T_{1}}-k_{1}\right) & \left(\frac{k_{r}}{T_{r} L_{s}^{\prime}}-j \frac{k_{r} \omega}{L_{s}^{\prime}}\right) \\
\left(\frac{L_{m}}{T_{r}}-k_{2}\right) & \left(-\frac{1}{T_{r}}+j \omega\right)
\end{array}\right]
$$




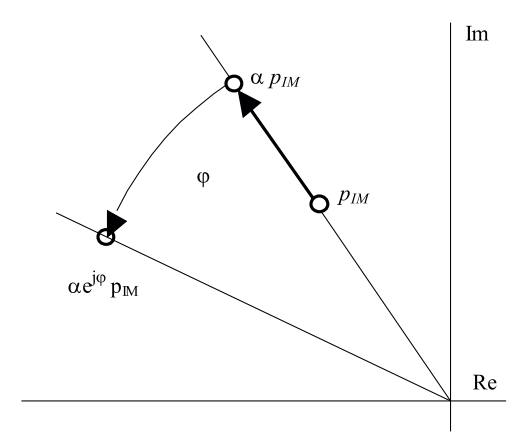

Fig. 2. Motor and observer pole placement

A special case of this type of the observer is the case when coefficients $k_{1}$ and $k_{2}$ will be chosen to be zero and then the observer matrix will be equal to the system matrix. This approach was used in [11]. But the quality of such an observer is not very good because there is no feedback from the model and system outputs difference ((6), (25)). Hence it is necessary to pay attention to the mentioned coefficients design.

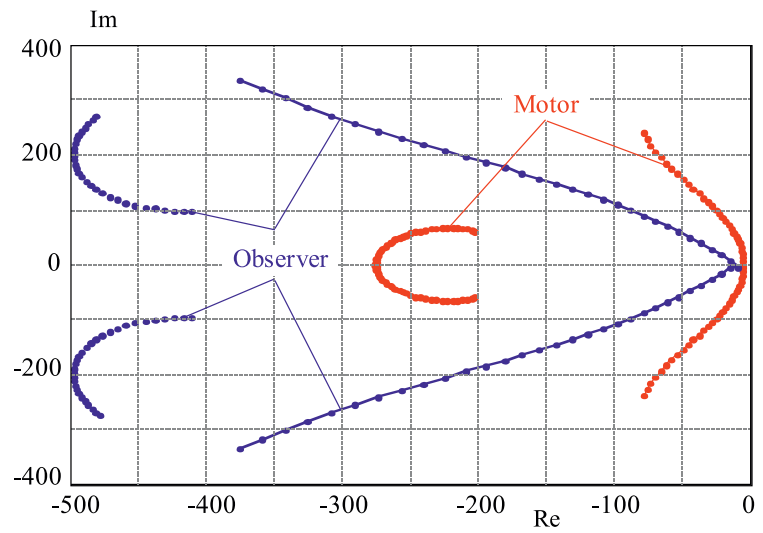

Fig. 3. Motor and observer poles for motor speed from interval -300 to $300 \mathrm{rad} / \mathrm{s}$ in continuous-time space

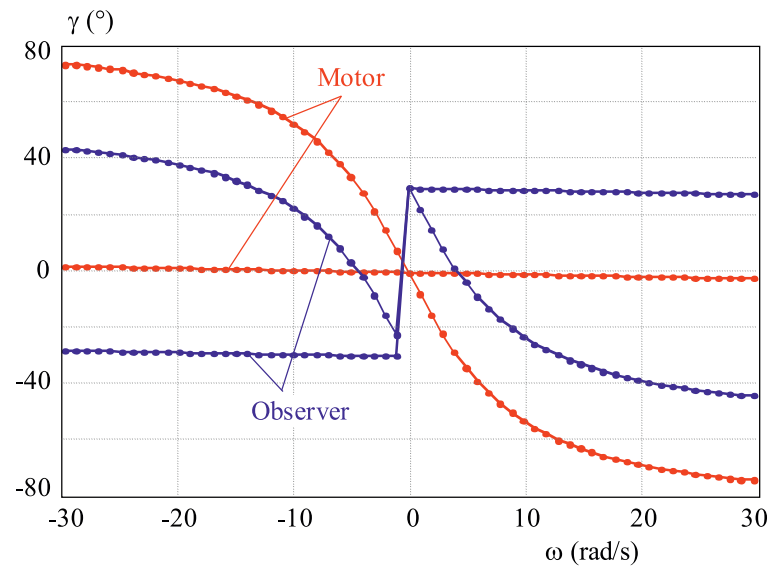

Fig. 5. Detail of the motor and observer poles angle for motor speed from interval -30 to $30 \mathrm{rad} / \mathrm{s}$ with step $1 \mathrm{rad} / \mathrm{s}$
For calculation of the $k_{1}$ and $k_{2}$ coefficients the observer matrix can be written as

$$
\boldsymbol{A}_{0}=\boldsymbol{A}-\boldsymbol{K} \boldsymbol{C}=\left[\begin{array}{ll}
\left(a_{1}-k_{1}\right) & a_{2} \\
\left(a_{3}-k_{2}\right) & a_{4}
\end{array}\right]
$$

\section{Observer poles placement as $p_{L O}=\alpha e^{j \varphi} p_{I M}$ with constant turn angle}

One of the often used possibilities how to place the observer poles is that the poles will be (in comparison with the motor poles) multiplied by factor and moreover turned by a fixed angle closer to the negative part of the real axis. The observer poles can be then expressed as

$$
p_{L O}=\alpha e^{j \varphi} p_{I M}
$$

Experiments with such chosen observer poles can be found in [8].

For calculating the gain matrix coefficients $k_{1}$ and $k_{2}$ next equations can be used

$$
\mathbf{g}=|g| e^{j \varphi}=|g|(\cos \varphi+j \sin \varphi)=g_{r}+j g_{i}
$$

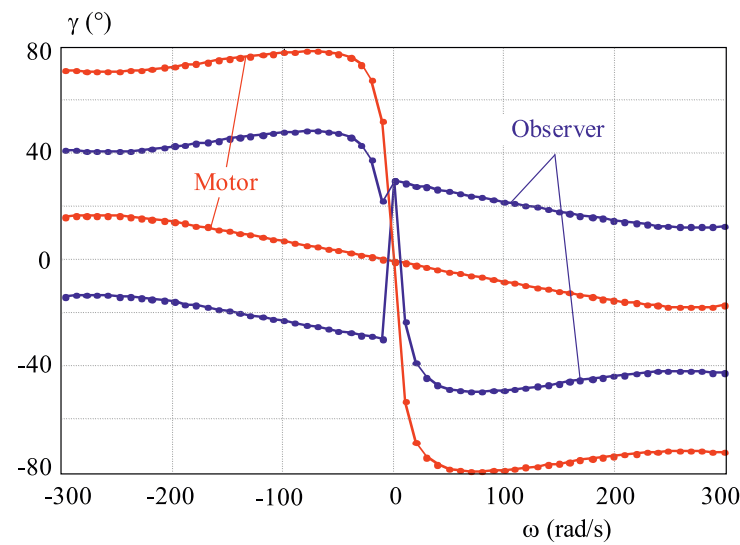

Fig. 4. Motor and observer poles angle for motor speed from interval -300 to $300 \mathrm{rad} / \mathrm{s}$

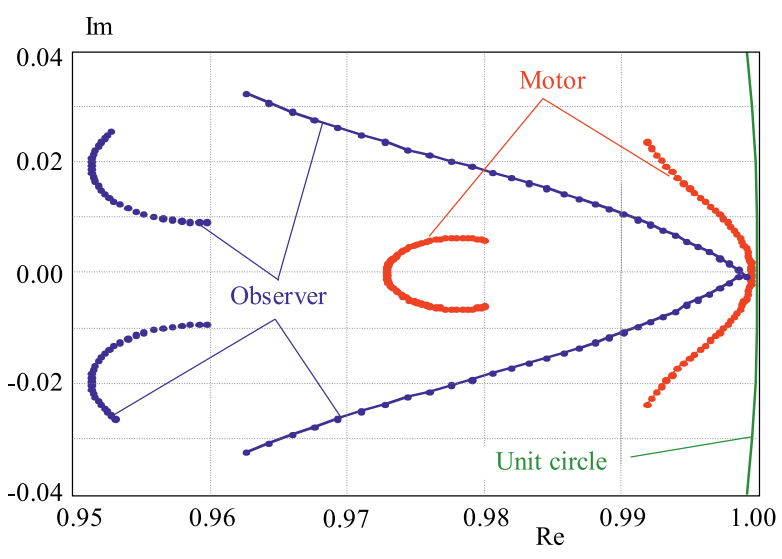

Fig. 6. Motor and observer poles position for motor speed from interval -300 to $300 \mathrm{rad} / \mathrm{s}$ in discrete-time space 
If the original motor poles would be

$$
p_{I M}=\left|p_{I M}\right| e^{j \xi}
$$

the observer poles can be written as

$$
p_{L O}=g p_{I M}=|g| e^{j \varphi}\left|p_{I M}\right| e^{j \xi}=|g|\left|p_{I M}\right| e^{j(\xi+\varphi)}
$$

That means it is possible to move the observer poles more to the left side and turn them by a requested angle which can improve the system behavior. In this case coefficients $k_{1}$ and $k_{2}$ can be written as

$$
\begin{aligned}
& k_{1}=(g-1)\left(\frac{1}{T_{1}}+\frac{1}{T_{r}}-j \omega\right) \\
& k_{2}=\left(g^{2}-1\right)\left(\frac{L_{s}^{\prime}}{k_{r} T_{1}}-\frac{L_{m}}{T_{r}}\right)-\frac{L_{s}^{\prime}}{k_{r}} k_{1}
\end{aligned}
$$

or in components form

$$
\begin{aligned}
& k_{11}=\left(g_{r}-1\right)\left(\frac{1}{T_{1}}+\frac{1}{T_{r}}\right)+g_{i} \omega \\
& k_{12}=\left(1-g_{r}\right) \omega+g_{i}\left(\frac{1}{T_{1}}+\frac{1}{T_{r}}\right) \\
& k_{21}=\left(1-g_{r}^{2}+g_{i}^{2}\right)\left(\frac{L_{m}}{T_{r}}-\frac{L_{s}^{\prime}}{k_{r} T_{1}}\right)-\frac{L_{s}^{\prime}}{k_{r}} k_{11} \\
& k_{22}=2 g_{r} g_{i}\left(\frac{L_{s}^{\prime}}{k_{r} T_{1}}-\frac{L_{m}}{T_{r}}\right)-\frac{L_{s}^{\prime}}{k_{r}} k_{12}
\end{aligned}
$$

It is necessary to mention that the changing sign of the turn angle is needed when the sign (direction) of the angular speed changes. (It will be expressed in the change of the $g_{i}$ parameter sign in equations (14)).

In Figs. 3 to 6 one can see that the observer poles, in comparison with motor poles, become quicker and the imaginary part of the dominant pole is relatively lower in comparison with the dominant motor pole, hence it becomes more stable. One can also see that in the very low speed areas, when the imaginary part of the motor poles is very small, the imaginary part of the observer becomes higher (in comparison with the motor poles) and furthermore when the speed crosses the zero line, the imaginary part of the observer poles changes discontinuously. This can have a negative influence at very low speeds mainly in the case of lower parameters precisions or higher noise in the measurements. In the figures one can see also a strange position of the quicker observer pole (in comparison with the equivalent motor pole). This is because the angle of the quicker motor pole is lower than the angle by which the observer poles are turned.

\section{Observer poles placement as $p_{L O}=\alpha e^{j \varphi} p_{I M}$ with flexible turn angle}

In the figures in the previous part it can be seen that if the observer poles are turned by a fixed angle with respect to the motor poles, undesired effects appear in the zero speed areas which can have a negative influence upon the observing. So the question is how to design the observer poles to ensure that a small change of the angular speed will not evocate a discontinuous change of the observer poles angle. Furthermore, the observer poles should be quicker than the motor poles and also should be relatively closer to the negative real axis also in the states with a very low speed.

If $p_{o 1}$ and $p_{o 2}$ are observer poles then the observer characteristic equation will be

$$
\begin{aligned}
& \left(s-p_{o 1}\right)\left(s-p_{o 2}\right)= \\
& =s^{2}-\left(p_{o 1}+p_{o 2}\right) s+p_{o 1} p_{o 2}=0
\end{aligned}
$$

If characteristic equation expressed form the observer matrix (8) is compared with the characteristic equation (15) then the equations for calculating $\mathrm{k} 1$ and $\mathrm{k} 2$ parameters can be derived

$$
\begin{aligned}
& k_{1}=a_{1}+a_{4}-\left(p_{o 1}+p_{o 2}\right) \\
& k_{2}=\frac{p_{o 1} p_{o 2}+a_{2} a_{3}-a_{4}\left(a_{1}-k_{1}\right)}{a_{2}}
\end{aligned}
$$

and after substitution

$$
\begin{aligned}
& k_{1}=-\left(\frac{1}{T_{1}}+\frac{1}{T_{r}}+p_{o 1}+p_{o 2}-j \omega\right) \\
& k_{2}=\frac{p_{o 1} p_{o 2}}{\frac{k_{r}}{T_{r} L_{s}^{\prime}}-j \frac{k_{r} \omega}{L_{s}^{\prime}}}+\frac{L_{m}}{T_{r}}-\frac{L_{s}^{\prime}}{k_{r}}\left(\frac{1}{T_{1}}+k_{1}\right)
\end{aligned}
$$

Using equations (17) the observer gains can be calculated for freely-chosen two observer poles, the next two observer poles will be complex conjugats to them.

If the observer poles are designed as -multiplication of the motor poles, we can get observer poles which are quick enough. If the observer poles are turned then by a defined angle, we can get also a better dumping of the system. But this angle can not be fixed, it should depend on the angular speed - or in other words - should depend on the motor poles. The aim will be to turn the observer poles closer to the negative part of the real axis but the poles should not get behind the axis even at a very small speed. So the observer poles should stay in the same quadrant as the motor poles. When the motor poles are

$$
p_{I M}=\left|p_{I M}\right| e^{j \xi}
$$

then for the observer poles ne can write

$$
p_{L O}=p_{I M} \alpha e^{j \varphi}
$$

where angle $\varphi$ will be calculated as

$$
\varphi=\lambda * \operatorname{nrm}(\pi-\xi)
$$




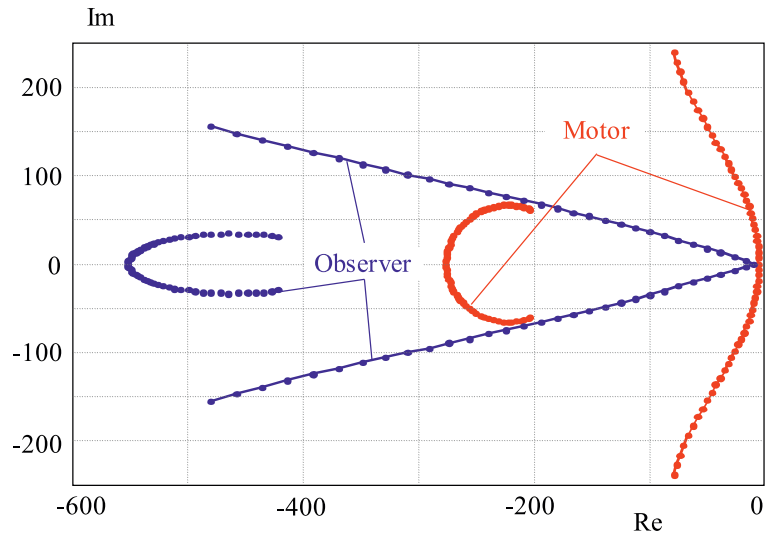

Fig. 7. Motor and observer poles for motor speed from interval -300 to $300 \mathrm{rad} / \mathrm{s}$ in continuous-time space

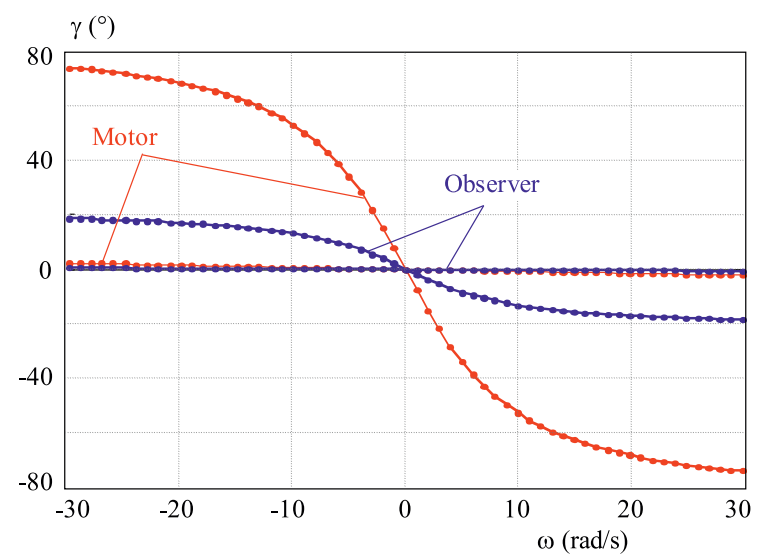

Fig. 9. Detail of the motor and observer poles angle for motor speed from interval -30 to $30 \mathrm{rad} / \mathrm{s}$ with step $1 \mathrm{rad} / \mathrm{s}$

Function $\operatorname{nrm}()$ recalculates the angle to be from the range $(-\pi, \pi\rangle$ and $\lambda$ is a real number from the range $\langle 0,1\rangle$ which defines how much will be the observer poles turned to the negative part of the real axis. For $\lambda=0$ the observer poles will not be turned anyhow (in comparison to the motor poles), for $\lambda=1$ the observer poles will be turned by an angle which ensures that the observer poles will be on the real axis. This approach could be described using figure Fig. 2 but the angle $\varphi$ will depend on the equivalent motor pole.

Figures 7 to 10 show the motor and the observer poles position during a change of the angular speed when the described method was applied.

The angular speed changes from te range -300 to 300 $\mathrm{rad} / \mathrm{s}$ (step $10 \mathrm{rad} / \mathrm{s}$ is marked by dots in the figures). In the figures only two poles are shown, the other two poles are complex conjugats to them. Angle $\gamma$ in figure Fig. 8 is expressed as the angle from the negative part of the real axis.

The observer was designed for $\alpha=2, \lambda=0.75$

In Fig. 7 to Fig. 10 can be seen that observer poles position is as expected. The position poles are moving continuously also in states with very low speed.

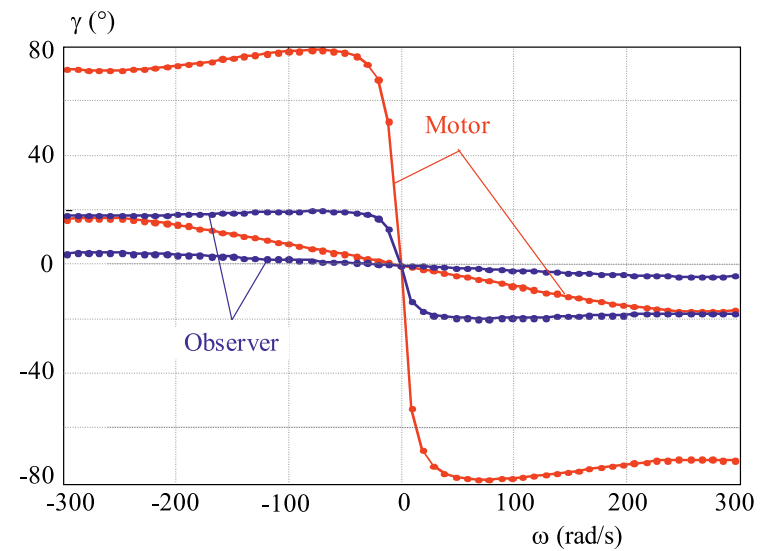

Fig. 8. Motor and observer poles angle for motor speed from interval -300 to $300 \mathrm{rad} / \mathrm{s}$

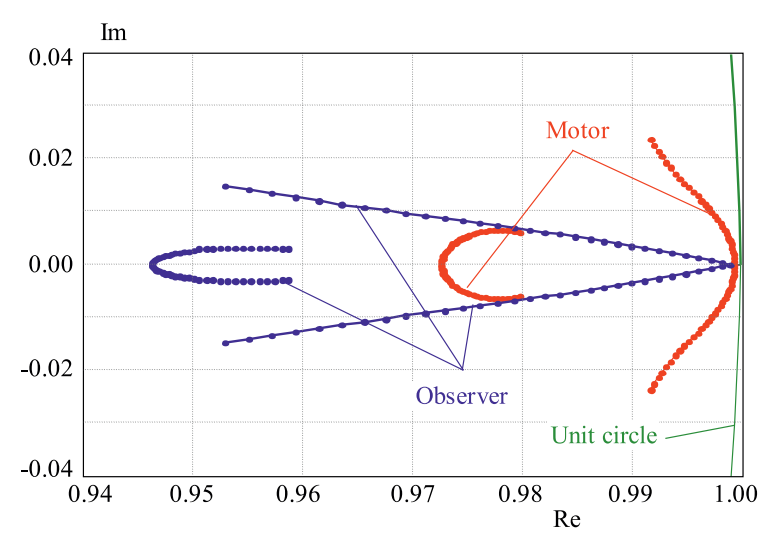

Fig. 10. Motor and observer poles position for motor speed from interval -300 to $300 \mathrm{rad} / \mathrm{s}$ in discrete-time space

\section{Adaptive speed observer}

There are more possibilities how to observe the angular speed in a servodrive with a Luenberger observer (used for observing the rotor magnetic flux). The first possibility is to extend the observer state variable vector by including the angular speed. But with this modification the ELO would become more complex and hence also calculation of the observer gain matrix $\mathrm{K}$ becomes more complex and also more time consuming. It is the reason why other methods are used for observing the angular speed in such cases. One of the most used structure is a structure based on a MRAS system shown in Fig. 11.

This structure was used as a speed observer in [13]. In [14], a part for observing the stator resistance $R_{s}$ was integrated into this structure and used in combination with a Kalman filter (which was used as a magnetic flux observer).

In [9], [10], [12] this structure was used with a motor model in the rotor coordinate system which led to the needs of converting the measured values into this coordinate system.

In [12] the mentioned adaptive system was expanded for observing the stator resistance $R_{s}$. The mentioned 


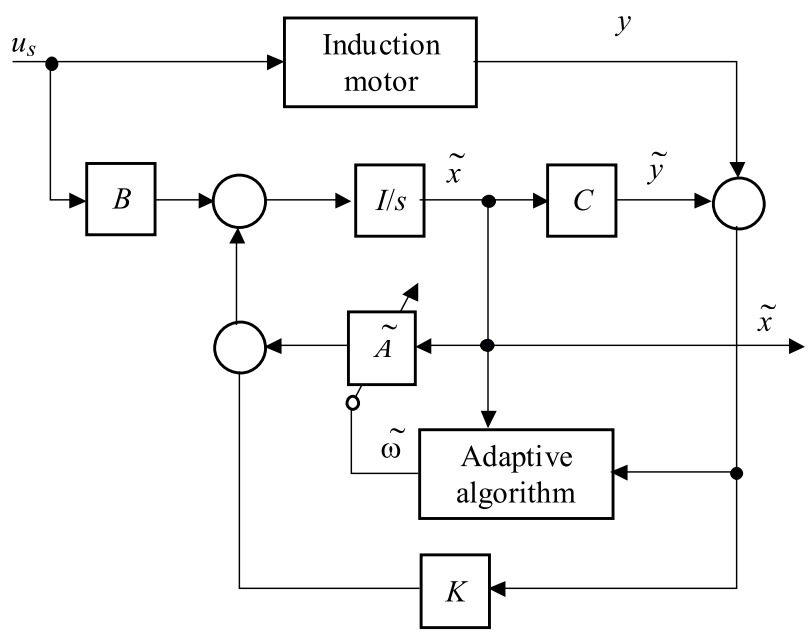

Fig. 11. Block diagram of the MRAS-based speed observer

articles use an adaptation algorithm derived using the Ljapunov stability theory.

As a candidate to the Ljapunov function the following fomula was chosen

$$
V=e^{T} e+\left(\tilde{\omega}_{r}-\omega_{r}\right)^{2} / \lambda
$$

where $e=x-\tilde{x}$ and $\lambda$ is positive constant.

After differentiation and a few steps this equation was obtained for angular speed observing

$$
\tilde{\omega}_{r}=K_{I \omega} \int\left(e_{i s \alpha} \tilde{\psi}_{r \beta}-e_{i s \beta} \tilde{\psi}_{r \alpha}\right) \mathrm{d} t
$$

To have better dynamic characteristics it is advisable to add also a proportional part to the equation

$$
\begin{aligned}
\tilde{\omega}_{r}= & K_{P \omega}\left(e_{i s \alpha} \tilde{\psi}_{r \beta}-e_{i s \beta} \tilde{\psi}_{r \alpha}\right)+ \\
& +K_{I \omega} \int\left(e_{i s \alpha} \tilde{\psi}_{r \beta}-e_{i s \beta} \tilde{\psi}_{r \alpha}\right) \mathrm{d} t
\end{aligned}
$$

The equation is represented in the stator coordinate system (as it was used in [13] and [14]). In those articles where the same equation was used in combination with a model in the rotor coordinate system, the quantities have to be converted to the rotor coordinate system. It is needed to mention that after differentiation of the $V$ function there appeared also items $e_{\psi r \alpha}, e_{\psi r \beta}$ which were neglected.

On the other hand for the motor model in the rotor coordinate system it is needed to convert the measured quantities to the rotor coordinate system and hence it is needed to know the angle of the rotor turn. There are coefficients $K_{P \omega}, K_{I \omega}$ in the presented equations. These coefficients are positive numbers. With a proper selection of these coefficients speed and quality of angular speed observing can be tuned.
For parameters these values were chosen

$$
\begin{aligned}
& K_{P \omega}=0.3 \\
& K_{I \omega}=3 \times 10^{4} \mathrm{~s}^{-1}
\end{aligned}
$$

\section{SIMULATION EXPERIMENTS}

Since the IM control and also observing is realized in a discrete-time area it is needed to convert the observer to the discrete shape. For the Luenberger observer in discrete-time it can be written

$$
\begin{aligned}
& \tilde{\boldsymbol{x}}(k+1)=\tilde{\boldsymbol{A}}_{d} \tilde{\boldsymbol{x}}(k)+\boldsymbol{B}_{d} \mathbf{u}(k)+ \\
& +\boldsymbol{K}_{d}\left(\boldsymbol{y}(k)-\boldsymbol{C}_{d} \tilde{\boldsymbol{x}}(k)\right)= \\
& =\boldsymbol{A}_{O d} \tilde{\boldsymbol{x}}(k)+\boldsymbol{B}_{d} \mathbf{u}(k)+\boldsymbol{K}_{d} \boldsymbol{y}(k) \\
& \tilde{\boldsymbol{y}}(k)=\boldsymbol{C}_{d} \tilde{\boldsymbol{x}}(k)
\end{aligned}
$$

For the motor model matrixes (defined by (2)) in discretetime domain it can be written (first order approximation was used)

$$
\begin{aligned}
& \boldsymbol{A}_{\boldsymbol{d}}=\left[\begin{array}{cc}
1-\frac{T}{T_{1}} & T\left(\frac{k_{r}}{T_{r} L_{s}^{\prime}}-j \frac{k_{r} \omega}{L_{s}^{\prime}}\right) \\
\frac{T L_{m}}{T_{r}} & 1+T\left(-\frac{1}{T_{r}}+j \omega\right)
\end{array}\right] \\
& \boldsymbol{B}_{\boldsymbol{d}}=\left[\begin{array}{c}
\frac{T}{L_{s}^{\prime}} \\
0
\end{array}\right] ; \quad \boldsymbol{C}_{\boldsymbol{d}}=\left[\begin{array}{ll}
1 & 0
\end{array}\right]
\end{aligned}
$$

and

$$
\boldsymbol{K}_{d}=\boldsymbol{K} T
$$

where $T$ is the sample time period. 


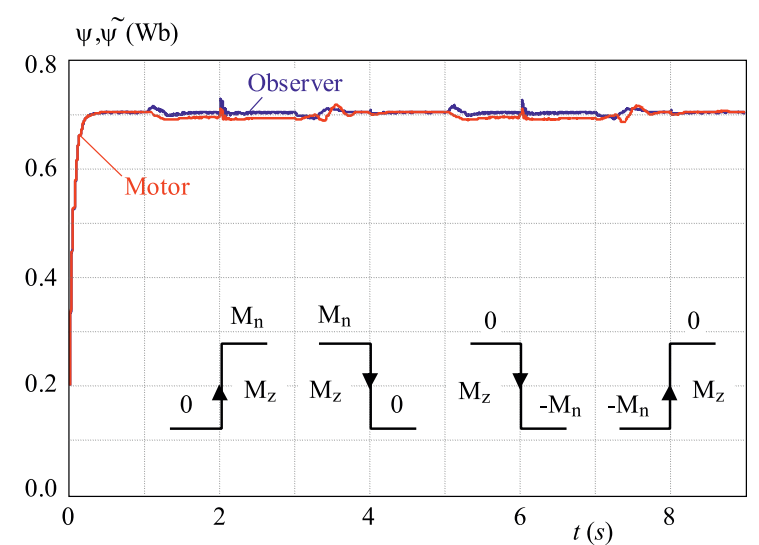

Fig. 12. Observed and real (from IM-model) magnetic flux magnitude

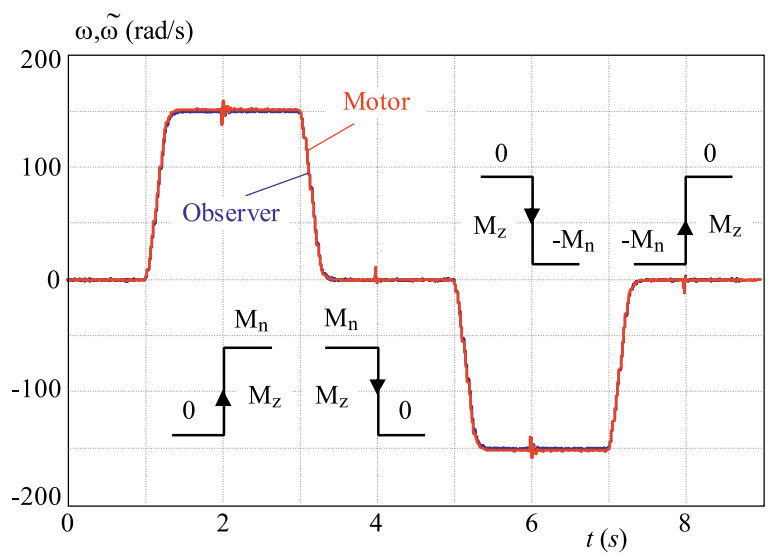

Fig. 14. Observed and real (from IM-model) speed

IM model parameters

\begin{tabular}{ll}
\hline$P_{n}$ & $=1.1 \mathrm{~kW}$ \\
$n$ & $=2840 \mathrm{~min}^{-1}$ \\
$p^{\prime}$ & $=1$ \\
$\cos \varphi$ & $=0.86$ \\
$\eta$ & $=0.71$ \\
$U_{n}$ & $=380 / 220 \mathrm{~V}$ \\
$I_{n}$ & $=2.6 / 4.5 \mathrm{~A}$ \\
$M_{n}$ & $=3.7 \mathrm{Nm}$ \\
$J$ & $=0.002 \mathrm{kgm}$ \\
$R_{s}$ & $=7.6 \Omega$ \\
$R_{r}$ & $=3.7 \Omega$ \\
$L_{s}$ & $=0.6015 \mathrm{H}$ \\
$L_{r}$ & $=0.6015 \mathrm{H}$ \\
$L_{m}$ & $=0.5796 \mathrm{H}$
\end{tabular}

The requested value of the magnetic flux modulus was set to $0.7 \mathrm{~Wb}$ (which is the nominal value). The steps of the load torque were $\pm 3.7 \mathrm{Nm}$ which is a value equal to the nominal torque of the used motor.

White noise with an amplitude of about $5 \%$ of the nominal current was added to the components of the

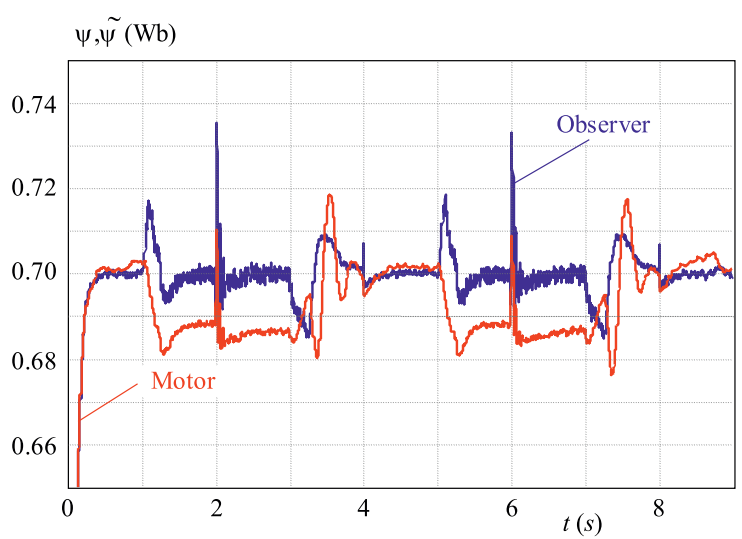

Fig. 13. Detail of the observed and real (from IM-model) magnetic flux magnitude

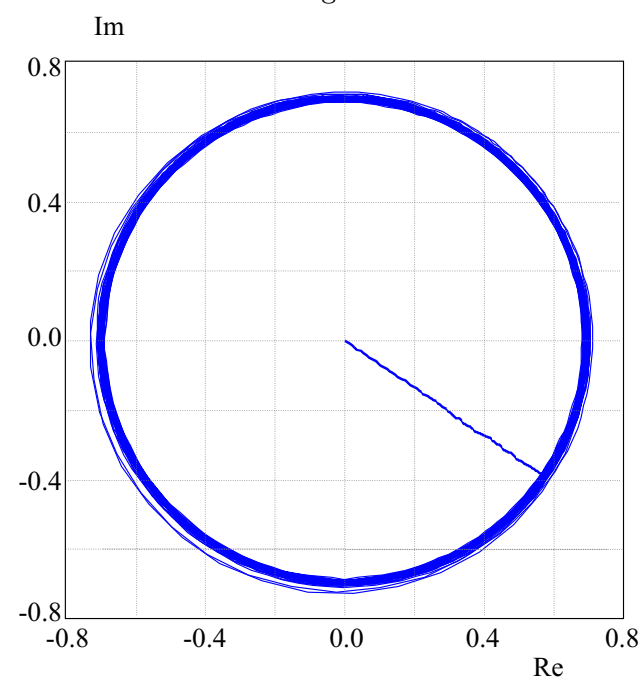

Fig. 15. Rotor magnetic flux vector

stator current. The sample time period was $T=0.1 \mathrm{~ms}$. Simulations were performed for the system controlled in the Direct Vector Control structure.

The following simulations were made with the described observer with $\alpha=2, \lambda=0.75$.

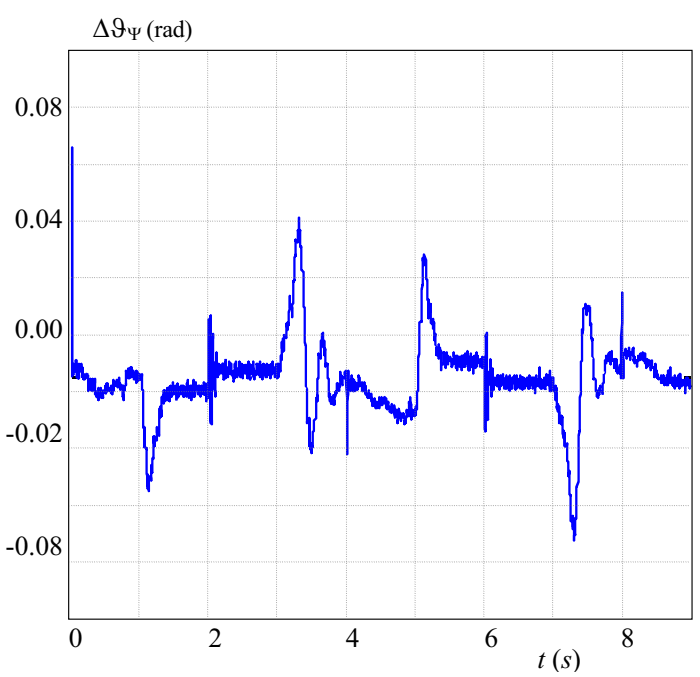

Fig. 16. Difference of the observed and real (from IM-model) rotor magnetic flux angle 


\section{DISCUSSION AND CONCLUSIONS}

The article concerns with the application of the extended Luenberger observer for observing the rotor magnetic flux of the induction motor. This observer was applied to an IM model in a complex form. For the observer with parameters $\alpha=2, \varphi=30^{\circ}$ (modulus of the observer poles was twice greaterthan the modulus of the motor poles, and the observer poles were turned by 30 degrees from the motor poles) the position of poles was analyzed during the speed change. There was seen some strange behaviour of the observer poles in the states, when the angular speed is very low (increasing imaginary part of the observer poles and discontinuous change of the observer poles, when the speed changed its direction). Then a new method was proposed for designing the observer poles position which suppressed the mentioned strange behaviour. For simulation purposes the parameters of the new method were chosen as $\alpha=2, \lambda=0.75$ where $\alpha$ is a parameter (similar to the previous case) ratio of the observer and motor poles modulus and $\lambda$ expresses the relative change of the observer and motor poles phase (for the phase of the observer poles will be the same as the phase of the motor poles, for the observer poles will be turned by an angle which ensures that the observer poles will be on the real axis). This method ensures that the phases of the observer poles will be always between the motor poles phases and the negative part of the real axis. Furthermore, the observer poles position will be changed continuously also when the angular speed changes its direction.

Simulation experiments were made in a structure of direct vector control with the described magnetic flux observer and adaptive speed observer. The simulation experiments show that the proposed observer can be used in speed servodrives with IM also in low speed areas.

\section{Acknowledgments}

This article was elaborated as part of the grant project VEGA 1/0690/09.

\section{REFERENCES}

[1] ABELOVSK, M.: Observers of state parameters of sensorless servo-drives with AM (Pozorovatele stavových veličín bezsnímačových servopohonov s AM), Thesis, Department of Automation and Control, FEI STU, Bratislava, 2003. (in Slovak)

[2] VAS, P.: Sensorless Vector and Direct Torque Control, Oxford University Press, New York, 1998.

[3] OHYAMA, K.-ASHER, G.-SUMNER, M. : Comparison of the Practical Performance and Operating Limits of Sensorless Induction Motor Drive using a Closed Loop Flux Observer and a Full Order Observer, EPE '99, Lausanne 1999.

[4] ARmstrong, G.-ATKinson, D. : A Comparison of Model Reference Adaptive System and Extended Kalman Filter Estimators for Sensorless Vector Drives, EPE '97, Pages 1424-1429, Trondhaim 1997.
[5] SCHAUDER, C. : Adaptive Speed Identification for Vector Control of Induction Motors without Rotational Transducers, IEEE Trans. Ind. Appl. 28 No. 5, September/October (1992).

[6] BEIERKE, S.-VAS, P.-SIMOR, B.-STROANCH, A. : DSPControlled Sensorless AC Vector Drives Using The Extended Kalman Filter, Intelligent Motion, 31-41, June 1997.

[7] Texas Instruments Sensorless Field Oriented Speed Control of Three Phase AC Induction Motor using TMS320F240, Texas Instruments Europe, France, 1998.

[8] GRIVA, G.-FERRARIS, P.-PROFUMO, F.-BOJOI, R. : Luenberger Observer for High Speed Induction Machine Drives based on a New Pole Placement Method, EPE 2001, Graz, 2001.

[9] MAES, J.-MELKEBEEK, J.: Adaptive Flux Observer for Sensorless Induction Motor Drives with Enhanced Dynamic Performance, EPE '99, Lausanne, 1999.

10] MAES, J.-MELKEBEEK, J.: Improved Adaptive Flux Observer for Wide Speed Range Sensorless Induction Motor Drives, Proc. Electromotion 6, 49-54, 1999.

11] LEE, C., M.-CHEN, C., L.: Observer-based speed estimation method for sensorless vector control of induction motors, IEE Proc. Control Theory Appl. 145 No. 3, May 1998.

[12] MAES, J.-MELKEBEEK, J. : Speed-Sensorless Direct Torque Control of Induction Motors Using an Adaptive Flux Obsetver, IEEE Trans. on Industry Applications v36 No. 3, 778-785 May/June 1993.

[13] KUBOTA, H.-MATSUSE, K.-NAKANO, T.: DSP-Based Speed Adaptive Flux Observer of Induction Motor, IEEE Trans. on Industry Applications 29 No. 2, 344-348 March/April 1993.

[14] MORA, J. L.-TORRALBA, A.-FRANQUELO, L. G.: A Speed Adaptive Kalman Filter Observer For Induction Motors, EPE 2001, Graz, 2001.

15] GACHO, J.: Sensorless speed servo-drive with AM and observation of state parameters by feedback observers (Bezsnmačový rýchlostný servopohon s AM s pozorovaním stavových veličín spä tnovzbovými pozorovatel'mi), Thesis, Insitute of Control and Industrial Informatics, FEI STU, Bratislava 2007. (in Slovak)

[16] ŽALMAN, M.-ABELOVSKÝ, M.-JOVANKOVIČ, J.: Riadenie v energetike, $137-142$, Open speed servosystems with AM (Otvorené rýchlostné servosystémy s AM), Bratislava 2000.

Received 7 September 2009

Juraj Gacho (Ing, PhD) was born in Slovakia in 1974. He received Ing. degree from the Faculty of Electrical Engineering and Information Technology, Slovak University of Technology in Bratislava in 1999 and $\mathrm{PhD}$ degree (in Automation and Control) from the same faculty in 2008. He is interested in position control, sensorless speed control, and IM states observers.

Milan Žalman (Prof PhD) was born in Slovakia in 1945. He received the MS and $\mathrm{PhD}$ degrees in automatic control from the Slovak Technical University (STU) Bratislava in 1968, 1981. He joined the Institute of Control and Industrial Informatics, Faculty of Electrical Engineering STU where he is currently professor of automation and control. He led or participated in projects for industry and national research projects from automation of technological lines. In the last decade he leads national research projects in motion control systems with AC motors. His professional experience is in the design of intelligent motion control, sensorless induction motor drives, fuzzy logic, neural networks and their application to servodrives, and implementation of DSP. 